\title{
Perspectives From Underserved African Americans and Their Health Care Providers on the Development of a Diabetes Self-Management Smartphone App: Qualitative Exploratory Study
}

Tai Barber-Gumbs ${ }^{1}$, BA; Ylva Trolle Lagerros ${ }^{2,3}$, MD, PhD; Laura M Sena ${ }^{4}$, RD, MSPH; Joel Gittelsohn ${ }^{4}$, PhD; Larry W Chang ${ }^{5}$, MD; Wayne W Zachary ${ }^{6 *}$, PhD; Pamela J Surkan ${ }^{7 *}, \mathrm{ScD}, \mathrm{PhD}$

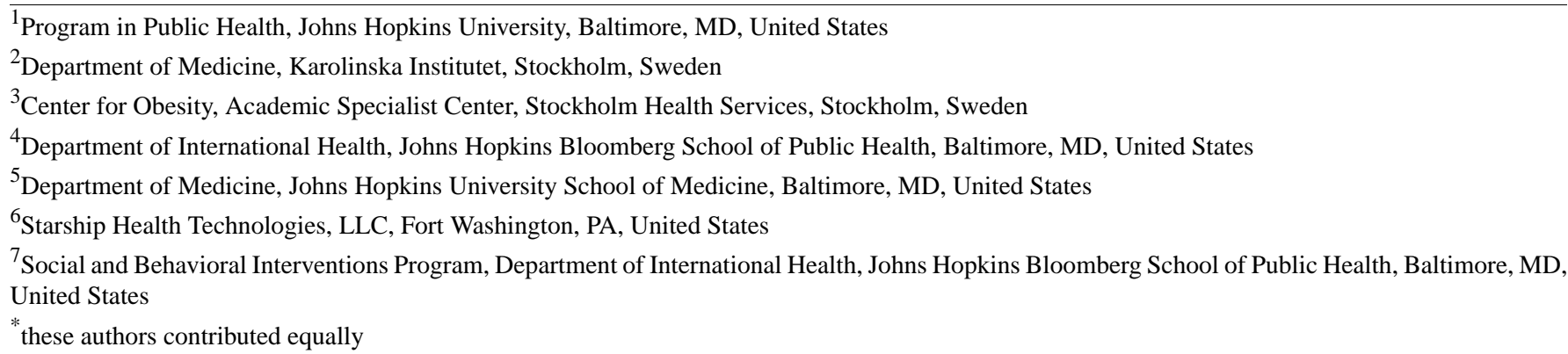

\section{Corresponding Author:}

Pamela J Surkan, ScD, PhD

Social and Behavioral Interventions Program

Department of International Health

Johns Hopkins Bloomberg School of Public Health

615 North Wolfe St

Room E5523

Baltimore, MD, 21205-2179

United States

Phone: 14105027396

Email: psurkan@jhu.edu

\section{Abstract}

Background: Type 2 diabetes mellitus (T2DM) affects approximately $10 \%$ of the US population, disproportionately afflicting African Americans. Smartphone apps have emerged as promising tools to improve diabetes self-management, yet little is known about the use of this approach in low-income minority communities.

Objective: The goal of the study was to explore which features of an app were prioritized for people with T2DM in a low-income African American community.

Methods: Between February 2016 and May 2018, we conducted formative qualitative research with 78 participants to explore how a smartphone app could be used to improve diabetes self-management. Information was gathered on desired features, and app mock-ups were presented to receive comments and suggestions of improvements from smartphone users with prediabetes and T2DM, their friends and family members, and health care providers; data were collected from six interactive forums, one focus group, and 15 in-depth interviews. We carried out thematic data analysis using an inductive approach.

Results: All three types of participants reported that difficulty with accessing health care was a main problem and suggested that an app could help address this. Participants also indicated that an app could provide information for diabetes education and self-management. Other suggestions included that the app should allow people with T2DM to log and track diabetes care-related behaviors and receive feedback on their progress in a way that would increase engagement in self-management among persons with T2DM.

Conclusions: We identified educational and tracking smartphone features that can guide development of diabetes self-management apps for a low-income African American population. Considering those features in combination gives rise to opportunities for more advanced support, such as determining self-management recommendations based on data in users' logs. 
(JMIR Form Res 2021;5(2):e18224) doi: 10.2196/18224

\section{KEYWORDS}

diabetes; mHealth; type 2 diabetes mellitus; diabetes self-management; mobile app; mobile phone

\section{Introduction}

As of 2020, an estimated 34.2 million people (10.5\%) had diabetes and it was the seventh leading cause of death in the United States [1]. Non-Hispanic African Americans have a notably higher diabetes prevalence $(11.7 \%)$ compared to non-Hispanic White people (7.5\%) [1]. To avoid complications, living with diabetes involves constant self-management, including exercise, healthy eating, glucose monitoring, and adherence to medications [2]. However, low-income African Americans and other minority populations face structural barriers to self-management, such as transportation-related issues, poor health literacy, and limited access to health services $[3,4]$. A study of almost exclusively Black and Hispanic participants suggested that individuals living with chronic conditions like type 2 diabetes mellitus (T2DM) have been turning toward technology to help with diet, exercise, and weight loss [5].

Research on the use of mobile health (mHealth) strategies to support individuals with chronic diseases, such as T2DM, has shown promising results, particularly with respect to positive lifestyle changes and self-efficacy [6]. Common features of current diabetes apps include encouraging self-management activities via reminders; collecting, storing, and displaying behavioral data on the user's physical activity, nutritional intake, and medication adherence; offering educational information on diet, nutrition, and lifestyle; and, to a lesser degree, enabling social media connections to other app users. A few make behavioral data available to health care providers, though generally not via the electronic health record [7-12]. Although the effects were small (ie, around a $0.5 \%$ change in glycated hemoglobin $\left.\left[\mathrm{HbA}_{1 \mathrm{c}}\right]\right)$, a meta-analysis of controlled trials of diabetes apps found that a range of apps significantly reduced $\mathrm{HbA}_{1 \mathrm{c}}$, an indicator of average blood glucose level over time [13].

Minority communities have had limited involvement in the development of mHealth interventions or in the comparative assessment of mHealth apps and their relevance to those communities [5]. Diabetes education that is culturally tailored to African Americans with T2DM can enhance self-management of the condition [14]. However, most diabetes apps on the market are not evidence based $[11,15]$ and likely do not reflect the needs of ethnic, minority populations such as African Americans.

A diabetes app, developed in collaboration with an underserved African American community, could serve as a culturally sensitive and cost-effective tool for diabetes self-management. Thus, we aimed to understand from this community what diabetes app features are perceived to benefit people with T2DM or pre-T2DM for diabetes self-management.

\section{Methods}

\section{Overview}

Between February 2016 and May 2018, we conducted exploratory qualitative research to inform the development of a diabetes management mHealth app, the Diabetes Networking Tool (DNT). Given the wealth of data on social support and its uses in an app, this paper is a companion to a recent separate publication related to desired social support mechanisms in an app [16].

\section{Setting}

The study took place in Southwest Baltimore, a low-income neighborhood where almost three-fourths of residents were African American [17]. In 2017, the median household income of the neighborhood was only slightly over half (ie, US \$24,946) that of Baltimore City overall (ie, US \$41,819). In 2017, the age-adjusted mortality rate for diabetes was 4.4 deaths per 10,000 in Southwest Baltimore, which can be compared to Baltimore City's average rate of 3.0 deaths per 10,000 [17].

\section{Recruitment}

Participants were initially recruited at residential buildings, a farmer's market, and a supermarket. Subsequent recruitment was done through snowball sampling. We used stratified, purposive sampling to achieve a distribution by gender and disease status (ie, prediabetes and T2DM versus close friends and family). Providers were recruited from health care facilities in the study area or we recruited those serving similar low-income populations. Nonproviders were incentivized with gift cards of US $\$ 40$ or US $\$ 50$, depending on the data collection activity.

The Johns Hopkins Bloomberg School of Public Health Institutional Review Board approved data collection. All participants provided oral informed consent, which included consent that deidentified data might be shared for research purposes.

\section{Study Sample}

A total of 78 people participated in this study. Inclusion criteria for nonproviders were being English-speaking adults who self-identified as having either prediabetes or T2DM or being a friend or family member of someone with prediabetes or T2DM, residence in the study community, and owning a smartphone. We included health care providers who served predominantly low-income African Americans with prediabetes or T2DM. Out of the 78 participants, $28(36 \%)$ self-identified as having prediabetes or T2DM, 30 (38\%) self-identified as being a friend or family member of someone with T2DM, and $20(26 \%)$ were health care providers (eg, diabetes educators, pharmacists, nurses, and physicians). Upon sign-in at the data collection activities, participants with T2DM and family or friends of persons with T2DM were asked to self-report their 
race, whether they identified as Hispanic or not, and whether others in their families had T2DM.

\section{Data Collection}

Data were collected in three phases. In Phase I, we held a series of 2- to 3-hour-long in-person interactive forums and interviews with people with T2DM and family or friends, one focus group, and multiple interviews with health care providers. The interactive forums and the focus group discussions were facilitated by public health graduate students, an anthropologist, or a public health faculty member who taught or was trained in qualitative research methods. Forums generally were larger than focus groups and used more interactive aides to guide the discussion, though the topics covered in the guide were very similar. Facilitators used semistructured interview guides and engaged participants in the creative process by asking them to make suggestions, offer ideas, and build on suggestions of other participants. Forums were audio-recorded and transcribed verbatim for analysis. Guides for the semistructured interviews also covered similar content, with the main difference being that they were longer and included more probes. Interviews were mainly carried out when it was logistically difficult to schedule a group session.

From Phase I, we analyzed participants' opinions on design concepts for a smartphone app [18]. In Phase II, we explored reactions of community members and providers to those design concepts through one community forum with people with prediabetes or T2DM and family or friends, as well as through interviews with providers, due to difficulties in organizing providers into groups. Using Phase II inputs, a revised design and prototype were created. Figures 1-3 provide prototype screen examples. Phase III data collection involved two forums that covered community members' perceived usefulness, usability, and learnability of the prototype, supplemented by interviews with 4 participants with T2DM.

Figure 1. Main navigation panel within the app.

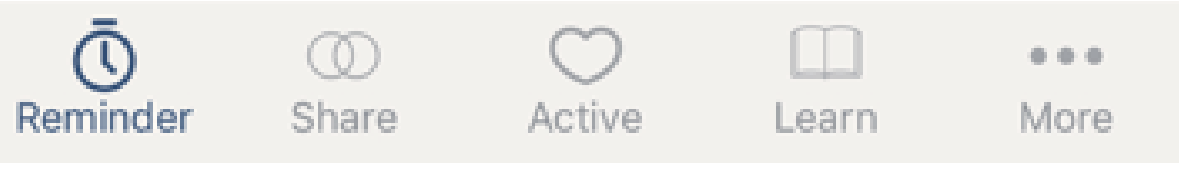

Figure 2. Initial detail screen when "Reminder" is selected from the navigation panel of the app.

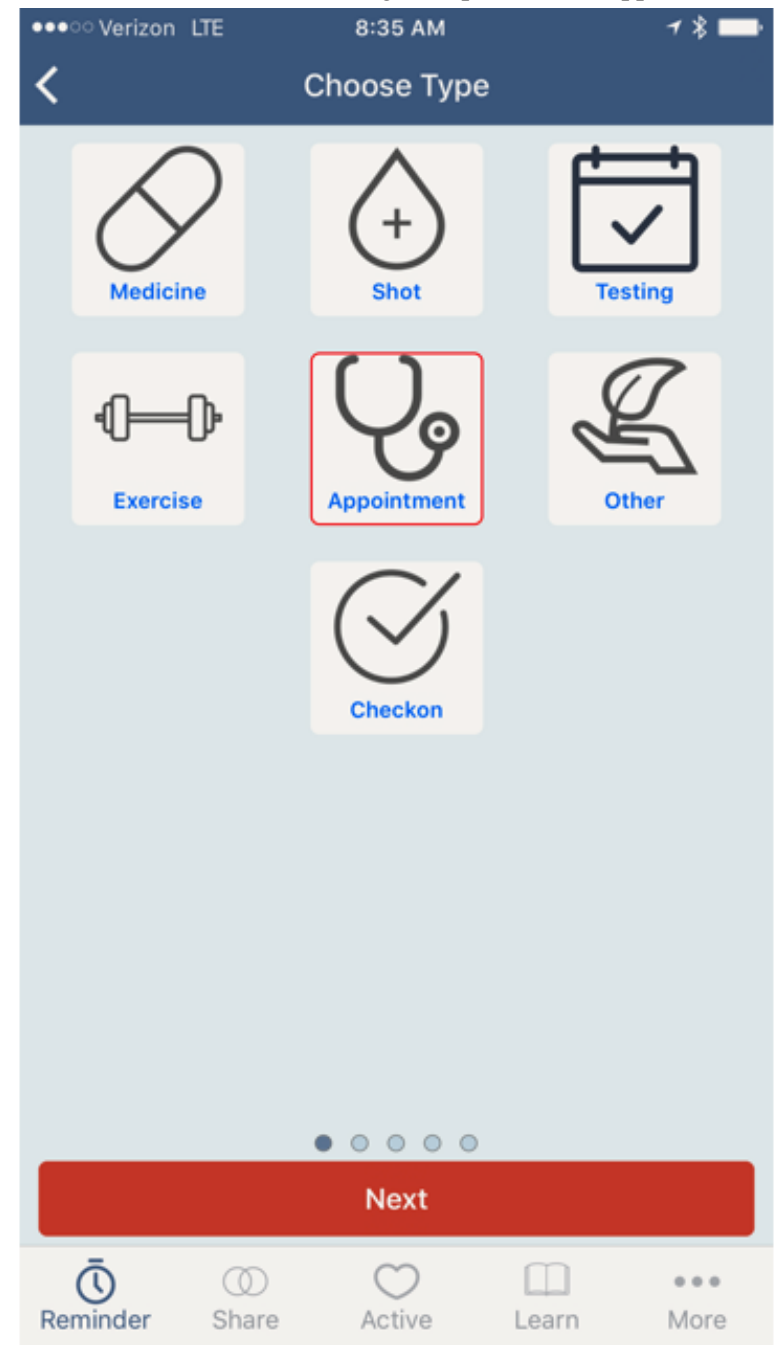


Figure 3. Initial screen when in the process of setting a new reminder in the app.

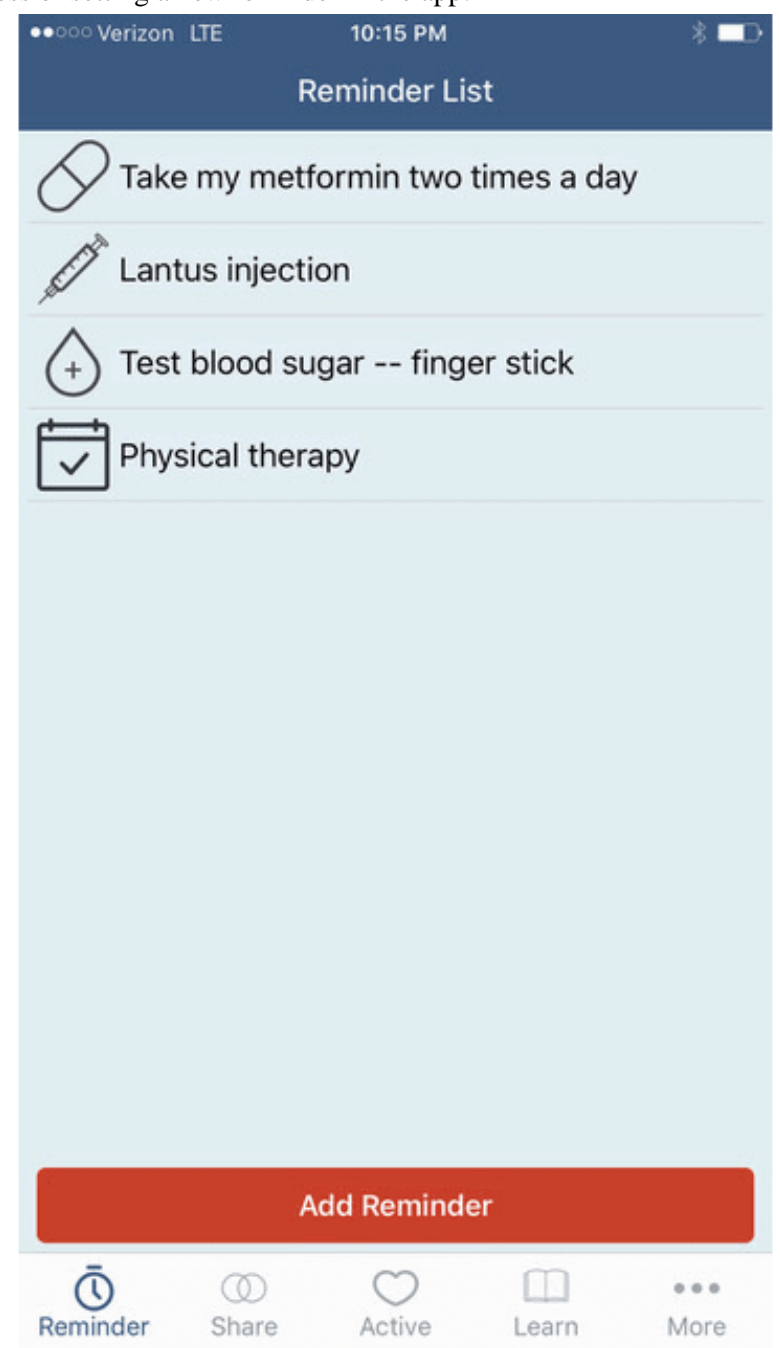

\section{App Prototype}

The results from the Phase I and Phase II data analyses were used to develop design concepts. Afterwards, a preliminary prototype of an app was developed. We presented static mock-ups of specific screens in this hypothetical app to community members in Phase II to receive comments, learn of perceived problems, and get suggestions to improve the design.

Revised designs were then animated to simulate dynamic sequences of app use. We presented this final interactive prototype app to users in Phase III for qualitative discussion and performed a quantitative assessment using the widely used System Usability Scale (SUS) [19,20]. This instrument uses a 10-item Likert scale to measure perceived usability and perceived learnability of a software interface.

\section{Qualitative Data Analysis}

Based on the community-generated ideas, we carried out thematic data analysis using an inductive approach to explore ideas about app use in diabetes self-management [21]. An inductive approach entails seeking patterns in the data without using a predetermined theory. Steps in our thematic analysis included the following: (1) reading and rereading transcripts to become familiar with that data, (2) generating initial codes, (3) looking for themes among codes, (4) reviewing these themes, and (5) defining and naming them [21]. Two researchers coded the data (LS and PS). Initial coding was done with the aid of the qualitative software ATLAS-ti, version 7 (Scientific Software Development $\mathrm{GmbH}$ ), followed sequentially with additional code refinement by another author to further capture the richness of the data (TBG). Memos were used throughout the analysis to facilitate theme development [22]. Data collection and transcription occurred concurrently, and transcripts were reviewed to elicit themes using the constant comparative method [23].

\section{Results}

\section{Overview}

Table 1 displays participants' demographic characteristics by type and data collection event. Community participants were adults who were evenly split between those diagnosed with T2DM or prediabetes $(28 / 57,49 \%)$ and family or friends $(30 / 57$, $53 \%)$. The majority of community participants $(37 / 58,64 \%)$ and of all participants $(47 / 78,60 \%)$ were female. A total of 4 people participated in forums across two different phases. No participants self-identified as Hispanic. Table 1 shows the number of unique individuals who participated as persons with prediabetes or T2DM or as family or friends. 
Table 1. Participant characteristics and data collection events.

\begin{tabular}{|c|c|c|c|c|c|c|c|c|c|}
\hline \multirow[t]{2}{*}{ Characteristic } & \multicolumn{4}{|c|}{$\begin{array}{l}\text { Prediabetes or } \mathrm{T}_{2} \mathrm{DM}^{\mathrm{a}} \text { and friend or family participants } \\
(\mathrm{n}=58), \mathrm{n}(\%)\end{array}$} & \multicolumn{4}{|c|}{ Provider participants $(\mathrm{n}=20), \mathrm{n}(\%)$} & \multirow[t]{2}{*}{$\begin{array}{l}\text { Total partici- } \\
\text { pants }(\mathrm{N}=78)\end{array}$} \\
\hline & $\begin{array}{l}\text { Initial fo- } \\
\text { rums (four) }\end{array}$ & $\begin{array}{l}\text { Preusability } \\
\text { forums (two) }\end{array}$ & $\begin{array}{l}\text { In-depth in- } \\
\text { terviews }\end{array}$ & Subtotal & $\begin{array}{l}\text { Initial FGD } \\
\text { (one) }\end{array}$ & $\begin{array}{l}\text { In-depth in- } \\
\text { terviews }\end{array}$ & $\begin{array}{l}\text { Paired inter- } \\
\text { view (one) }\end{array}$ & Subtotal & \\
\hline Total by event & $41(71)$ & $13(22)$ & $4(7)$ & $58(100)$ & $9(45)$ & $9(45)$ & $2(10)$ & $20(100)$ & $78(100)$ \\
\hline Gender: male & $15(26)$ & $5(9)$ & $1(2)$ & $21(36)$ & $5(25)$ & $4(20)$ & $1(5)$ & $10(50)$ & $31(40)$ \\
\hline $\begin{array}{l}\text { Race: African } \\
\text { American }\end{array}$ & $40(69)$ & $13(22)$ & $4(7)$ & $57(98)$ & $5(25)$ & $4(20)$ & $1(5)$ & $10(50)$ & $31(40)$ \\
\hline $\begin{array}{l}\text { T2DM status: predi- } \\
\text { abetes or } \mathrm{T} 2 \mathrm{DM}^{\mathrm{c}}\end{array}$ & $15(26)$ & $10(18)$ & $3(5)$ & $28(49)$ & $\mathrm{N} / \mathrm{A}^{\mathrm{d}}$ & N/A & N/A & N/A & N/A \\
\hline
\end{tabular}

aT2DM: type 2 diabetes mellitus.

${ }^{b}$ FGD: focus group discussion.

${ }^{\mathrm{c}}$ One person in the forums did not indicate their T2DM or prediabetes status and was not counted here as having T2DM or prediabetes (n=57).

${ }^{\mathrm{d}}$ N/A: not applicable; T2DM status was not applicable to providers.

We identified three main themes that identify desired goals that a smartphone app could help achieve, including help in (1) getting access to health resources, (2) delivering patient education about T2DM, and (3) supporting the diabetes self-management process.

\section{Finding and Accessing Health Resources}

All three types of participants reported that accessing care, medication, and testing resources were major barriers to self-managing diabetes. A provider explained the following:

They're [people with diabetes] eligible mostly for Medicaid, but for whatever reason they don't have insurance and they don't have funds for their medication. We have a couple of clients who have used the ER [emergency department] for getting their medication... We also see a lot of times people are running into challenges with getting supplies they need-like the glucose monitor, the lancets, the strips.

Several participants described how an app could make it easier to find free or discounted medication and medical supplies. For example, an individual with T2DM suggested the following:

You could talk to the app like, "Hey I lost my medicine, I don't have the insurance to pay for it. Is there some place I can go to get a free meter, a place for free testing strips, a pharmacy that may give out free insulins or medications?"

An app could also function as an alternative to computers. A patient explained how in the following quote:

People [in the study community] don't have access to the computer where they can actually go online and find [the discounts] and then end up waiting until the last minute or say, "Well, I can skip this," and you can't skip a dose. I tried it, believe me. I have been diabetic for over 20 years, and it's in my family. I've seen in my family a lot of missing toes.

An app could inform people with T2DM and/or their family or friend caregivers about affordable resources, such as free or low-cost medications, testing supplies, and/or healthy foods.
Participants agreed that the community does provide resources, but that people with T2DM are not aware that they are available. One provider explained, "It is a city, so the resources are there...it's just being aware of the resources." A patient stated, "If I don't know what's going on, nine times out of ten, I am not going to come out [to access resources] if I don't know."

Some participants expressed how an app could help people with T2DM find free resources to help with self-management. Others thought user posts on social media could help address such resource-finding problems. For instance, "If I wanted to post something, what would it be? I'd post locations for farmer's markets, community gardens." One provider suggested the following:
We tell our patients to go to-it's called Baltimore Free Farm on Arch Street-and every Wednesday they literally give away food and there's so many people when they come to their appointment and they say, "I don't have money to eat anything let alone something healthy." So, I think if a careful search is done of those resources and that's included on the app, that would be tremendous.

\section{Need for More Information About Diabetes}

Participants agreed that more information was desired about prediabetes and T2DM self-management and that an app could provide accurate T2DM information in lay terms. T2DM participants expressed how lack of knowledge discouraged them from seeking medical care:

I really don't know nothing about diabetes. So, I be like hesitant to go back to the doctor, because I don't want to start taking stuff that I don't know nothing about.

Some participants with T2DM discussed a need for an app to help fill the information gap:

I think if it could be kinda like Siri, if you can talk to it and ask it questions, then that would probably be good too...if you could ask the app questions like 
"What happens if I don't take my insulin for two days?"

Nonetheless, because of concerns about false information being spread on an app platform, participants suggested this information could be based on reliable sources (eg, the State Department of Health and Mental Hygiene).

\section{Active Support for Diabetes Self-Management Tasks and Activities}

\section{Overview}

The third area in which participants suggested an app could help was in self-management itself, by structuring and automating some repeated care tasks in T2DM (eg, taking medications and tracking blood glucose). Suggestions from all three types of participants fell into two interrelated areas: (1) app support for recording and tracking behaviors and testing data relevant to T2DM self-management and (2) a higher level of structure for self-management, to make it easier to adhere to and keep motivated.

\section{Logging and Tracking Information}

Participants expressed that if people with T2DM could track their progress and receive encouragement, then they would be likely to follow through with diabetes self-care plans. Some participants suggested that tracking could allow people to input their diabetes care information, such as $\mathrm{HbA}_{1 \mathrm{c}}$ levels, and to set reminders for care activities, such as when to exercise. A person with T2DM explained as follows:

That's how we know who's cheating, and who's not checking their sugars and things like that; in keeping a record, you can see when I did my last finger stick, so I know what it was.

Likewise, several providers expressed frustration about how patients forget their glucose monitors, yet they noted how most people with T2DM bring their phones to the doctor's office. Providers suggested that if patients registered health data on their phones, it would be easier to track what they were doing. A provider explained as follows:

\section{In my last job...they would bring their glucose monitor and it would just link to our computer and we would be able to download all of their data and it would give us a graph and we would be able to see trends and patterns and whether they are truly checking or not...I would like that information [on an app]}

By tracking self-management behaviors, people with T2DM could be held accountable to their health care providers. Friends and family members were also interested in having access to health information stored on an app so that additional support could be given. A friend or family member of a person with T2DM described this view as follows:

[The person with diabetes] can share it with me. It's another way you can help them, so when you go to the doctor and you have three months [of tracking], and they are able to send this through the app to the doctor's office and they see this, then they can know what to do to change your regimen.
In addition to monitoring progress, participants wanted an app that could remind people with T2DM to stay on track with their diabetes care plan. A participant with T2DM explained as follows: "Just something to keep the diabetes in the front of the brain instead of the back of the brain." Moreover, an app that has a reminder function could help people with T2DM remember their appointments or to refill medications. A provider pointed out the following: "We have a really high no-show rate here in West Baltimore, so a reminder for appointments is good."

\section{Encourage Engagement With Self-Management}

For persons with T2DM, self-management is a process that requires constant attention. Difficulties with diabetes self-management often lead to psychological distress and decreased adherence [24,25]. Participants suggested that, for the sake of further encouraging people with T2DM to stick with their care plans, an app should incorporate a goal-setting mechanism based on feedback and reward. By setting diabetes-related goals, a friend or family member explained that someone with T2DM could more easily achieve them:

$$
\begin{aligned}
& \text { The most important things would be to set a goal for } \\
& \text { them at the beginning-maybe weight loss, maybe } \\
& H b A_{1 c}-\text { so they can follow it and figure out how to } \\
& \text { get to that goal. }
\end{aligned}
$$

Then, by providing feedback on those goals via an app, patients would know the steps needed to stay on track with their health management plan. Finally, by setting goals and tracking one's progress toward them, enabled by the data recording and tracking function, an app could help evaluate progress, ideally in conjunction with a health care provider, and give feedback. A provider recommended the following:

The app should be able to analyze the data that the patient is putting in there and give them some feedback. "Oh, gee...your blood sugar has been in goal for the last five days - congratulations!"

This goal-setting, tracking, and feedback structure would enable positive feedback to encourage a person with T2DM to persist with a self-management plan and pinpoint specific problems to work on. Participants suggested that an app could provide, in addition to praise and focused constructive feedback, tangible diabetes-related rewards for people who are doing well. A provider proposed the following:
Maybe if they lose five pounds, they can get a discount on their gym membership for a month, or if they keep their blood sugar in control for two weeks, then maybe they get a week's supply of fresh vegetables from the farmers' market...Really, the ultimate reward is going to be that they preserve their health.

\section{Translation to App Design}

Our qualitative data analysis then led to the design of a preliminary prototype app with the following user functions: (1) setting reminders to engage in self-management behaviors (Reminder), (2) sharing information with other users of the app (Share), (3) finding other persons to engage in physical activities as part of T2DM self-management (Active), and (4) learning more about T2DM and related areas (Learn). The navigation 
design for the app was realized as a navigation panel of four glyphs at the bottom of the screen that corresponded to these four functions, as shown in Figure 1. The navigation panel also included a More glyph that could be used to navigate to a group of settings, as shown in Figure 1. Details on the process of functional and navigation design can be found in Zachary et al [18].

The Reminder and Active functions correspond directly to one of three themes discussed above, specifically "supporting the diabetes self-management process through the app." The Reminder function allows users to create reminders for the self-management activities, while the Active function connects users to a local social network of other app users in order to find others to participate, some with whom the user could plan regular physical activity. The Learn function was based on the theme of "delivering patient education about T2DM." It takes the user to lists of curated information from health experts, organized into categories of information needs that repeatedly arose in the forums (eg, information on diabetes, nutrition, exercise, and medications). The Share function provides functionality for sharing information with other local app users. One key purpose of this function is to share information on access to local health resources and opportunities, thus addressing the theme of "getting access to health resources."

A more detailed example of one function (ie, Reminder) begins in Figure 2. It shows the initial page of the interaction once Reminder is selected; the user's list of current reminders is shown, as is an option to create a new one. The user can tap an existing reminder to view or change it, or they can tap Add Reminder at the bottom of the screen. This takes the user to a palate of glyphs representing different self-management activities, as shown in Figure 3. From there, the user can select the type of reminder and begin the process of setting the details of that reminder.

\section{App Usability Assessments}

We collected data on the prototype app's perceived usability through two preusability forums (see Table 1). In each forum, participants were introduced to the DNT concept and exposed to the DNT prototype app via an interactive walk-through of the app. A facilitated discussion followed, which covered the prototype, its perceived match to its purpose, its usability and perceived strengths, its weaknesses, and possible improvements. SUS data were analyzed numerically using algorithms defined by Sauro [20]. Out of 13 participants, 12 (92\%) completed surveys were returned, and 2 surveys were discarded because the instructions were not followed. The mean SUS score of the usable surveys was 85.5 (SD 22.5), placing the DNT app above the $90^{\text {th }}$ percentile of all systems assessed with the SUS. While this score was very high, the sample $(\mathrm{n}=10)$ was small (ie, $\mathrm{N} \geq 12$ is recommended for SUS analysis) [26] and the variability was high (SD 22.5). Also, participants did not directly interact with the app but observed its use on the user's phone. Because the participants did not physically interact with the app, we use the term preusability forum, rather than usability forum. The high mean score suggests that app functionality and interface design were consistent with the needs identified.

\section{Discussion}

\section{Principal Findings}

In soliciting perspectives in a high-risk community from people with prediabetes and T2DM, as well as from formal and informal caregivers, we found that an app was desired that could (1) address some problems with access to health resources, (2) provide patient education on diabetes and risk factors, and (3) actively support self-management through tracking and encourage long-term adherence to self-care plans.

While some diabetes apps link patients to health resources and providers [27,28], recent comparative reviews did not include addressing financial barriers to diabetes self-management as a comparison criterion [7-11,29]. Moreover, while many apps focus on tracking of self-management adherence, the comparative review articles also did not cover comparisons of features intended to improve long-term user engagement with the app that would be required for effective long-term tracking. These absences suggest that such features were generally lacking.

Low-income families experiencing stress are less likely to be confident of receiving health care and less likely to receive it regardless of insurance coverage [30]. The problem of limited access to health care for low-income families is substantial in the United States. This could be attributable to the complexity of insurance coverage and the need for out-of-pocket funds to meet co-pays [31,32]. This complexity may explain an inconsistency in our data. The data suggested that participants could perceive health services as being available (eg, reporting having insurance through the publicly funded Medicare and/or Medicaid programs), while also reporting not having access to medications. Medicaid, which insures eligible low-income persons, and Medicare, which insures all persons over 65 and eligible disabled persons, have prescription drug components. However, those programs do not cover the full cost of many medications. Thus, they can levy substantial out-of-pocket costs for patients with chronic illness, such as T2DM patients, who require medications year-round [33,34].

A second inconsistency in our data is less easily explained. Participants reported having a smartphone but not being able to access websites with prescription discounts. It is possible that the participants did not know that they could access those websites from their phones or that their cell connections lacked the bandwidth to easily view those websites. Both would be interesting subjects for further research.

While not able to solve the more structural complex problems of lack of insurance and problems with access, our results suggest that an app with a function that would allow community members to post and share information about discounted or free medication and testing supplies in their area would be useful. Given the existence of primary care interventions where social workers check for social and welfare programs that could cover benefits that people with T2DM are not aware of [35,36], an app including this feature would fulfill this need at a lower cost.

This research points to another underexplored way that a diabetes app could benefit the community-by presenting 
curated information about T2DM so that people recognize and understand how to manage symptoms. Low-income, racial and ethnic minority populations underestimate their chance of developing diseases, which is a risk factor for not seeking regular health care [37]. A US study with a 77\% non-White sample found that knowledge gaps were pervasive, yet knowledge about diabetes risk was a motivating factor for better management [38]. This underscores the importance of finding ways to disseminate information about $\mathrm{T} 2 \mathrm{DM}$ to these populations.

To our knowledge, research has not examined how effective the consumption of health information among people with diabetes who use mHealth apps has been for self-management; however, apps may be superior to other forms of communication (eg, computers and books) for their convenience, mobility, and timely access to information [39]. There has been rapid adoption of smartphone technology in the United States, even among older and poorer segments of the population [40]. Given this, by making information about chronic disease easily accessible, an app might enable people with T2DM to better navigate diabetes management.

This research indicates interest in app features that focus on maintaining the long-term engagement of people with T2DM in self-management. Although long-term engagement is the ultimate goal, Kitsiou et al concluded in their review that they could only comment on short-term diabetes app studies, due to the lack of studies with long-term follow-up [41].

Regarding participants' desires for logging and tracking features, two reviews of 181 and 143 diabetes management apps for a medication reminder feature showed that only $56 \%$ and $58 \%$ of apps had such a function, respectively $[42,43]$, in spite of the fact that those that did had characteristics identified as likely to be effective [43]. Moreover, logging and tracking are typically applied only to a few aspects of self-management, with logging of nutritional intake and blood-glucose testing being more common, and logging of medication adherence being the least common [12]. This point is particularly relevant given challenges in self-management because of residents' low-income and minority status. Participants valued positive feedback and encouragement that could be enabled by data recording and tracking and automated data analysis, suggesting these two features may be helpful to support self-management. This may be particularly important, because participants often reported not having a consistent primary care provider over time and/or moving among several health systems, meaning that their electronic patient records would likely be incomplete and spread across many different computer systems. In such cases, the self-management log created by the user's app may be the only longitudinal data available to the provider for that patient.

One more enhancement suggested by participants was to get feedback from providers using tracked data [5]. An analysis of existing diabetes apps showed that improvements in $\mathrm{HbA}_{1 \mathrm{c}}$ levels, in conjunction with diabetes app use, were highly related to feedback from health care providers [13]. For example, dietary logs in combination with medication adherence, glucose testing, and physical activity logs could anticipate situations that might lead to degraded glucose management and alert the app user to take preventive actions.

Gamified smartphone apps fulfill a psychological need for satisfaction and feelings of accomplishment [44-46]. Health gamification can be applicable to an array of health conditions, including diabetes [46-48], and could directly extend from the engagement-enhancement features envisioned by our study participants. Gamification can lead to greater engagement and more persistent use. Positive feedback, driven by the app's analysis of recorded and tracked data, can trigger more gamified feedback, such as earning badges and/or setting up challenges with others. Such features can encourage people to persist in self-management by making it fun.

\section{Strengths and Limitations}

Multiple perspectives from different types of participants enabled triangulation of the findings. Another study strength was the participatory nature of data collection that incorporated voices of people traditionally overlooked in app development [5].

A study limitation was that most participants with prediabetes and T2DM were African American women, limiting the transferability of these findings. We lacked information on participant age and socioeconomic status, though our impression is that most participants with T2DM were in midlife or older and that they were low-income persons, as they all resided in a disadvantaged neighborhood. Furthermore, unless identifiable by the quote itself based on the audio recordings, we could not always distinguish participants with prediabetes and T2DM versus friends and family.

Finally, the interactive app prototype developed as part of this research did not, and could not, address all the functionality suggested because of the limited exploratory scope of the project. Specifically, it did not attempt to address more complex issues, such as gamification and longitudinal analysis of logged self-management data. Thus, while we identified community-driven ideas for diabetes self-management app features, the feasibility of implementing these features still needs further study.

\section{Conclusions}

In conclusion, despite the proliferation of diabetes mHealth apps [49], a dearth of information exists concerning the usage needs of these apps from African Americans with T2DM and the people who help them with disease management. Some needs uncovered in our study have been relatively uncommonly reported in the literature, such as lack of awareness of available social and welfare programs, of affordable health insurance, and of available, affordable, and local sources of healthy foods. Other needs identified correlate with those of T2DM patients in general (eg, support for self-management, encouragement, and engagement). App features should facilitate addressing these needs and consider incorporating, for example, tracking and gamification features. Future research may extend these findings and assess the feasibility of, and test apps with, these features. 


\section{Acknowledgments}

We are grateful to the study participants for sharing their views and taking part in the study. This work was supported by the National Institute of Nursing Research of the National Institutes of Health (R21NR015577), the National Institute of Diabetes and Digestive and Kidney Diseases (R43DK119079), and the Swedish Research Council for Health, Working Life and Welfare (2016-00985). The funding sponsors had no role in the study design; in the collection, analysis, and interpretation of data; in the writing of the report; and in the decision to submit the article for publication.

\section{Conflicts of Interest}

None declared.

\section{References}

1. Centers for Disease Control and Prevention. National Diabetes Statistics Report, 2020: Estimates of Diabetes and Its Burden in the United States. Atlanta, GA: Centers for Disease Control and Prevention, US Department of Health and Human Services; 2020. URL: https://www.cdc.gov/diabetes/pdfs/data/statistics/national-diabetes-statistics-report.pdf [accessed 2021-01-27]

2. Type 2 diabetes. National Institute of Diabetes and Digestive and Kidney Diseases. 2017 May. URL: https://www. niddk.nih.gov/health-information/diabetes/\%20overview/what-is-diabetes/type-2-diabetes [accessed 2018-12-17]

3. Kulhawy-Wibe S, King-Shier KM, Barnabe C, Manns BJ, Hemmelgarn BR, Campbell DJT. Exploring structural barriers to diabetes self-management in Alberta First Nations communities. Diabetol Metab Syndr 2018;10:87 [FREE Full text] [doi: 10.1186/s13098-018-0385-7] [Medline: 30524507]

4. Park S, Zachary WW, Gittelsohn J, Quinn CC, Surkan PJ. Neighborhood influences on physical activity among low-income African American adults with type 2 diabetes mellitus. Diabetes Educ 2020 Apr;46(2):181-190 [FREE Full text] [doi: 10.1177/0145721720906082] [Medline: 32100614]

5. Vangeepuram N, Mayer V, Fei K, Hanlen-Rosado E, Andrade C, Wright S, et al. Smartphone ownership and perspectives on health apps among a vulnerable population in East Harlem, New York. Mhealth 2018;4:31 [FREE Full text] [doi: 10.21037/mhealth.2018.07.02] [Medline: 30221166]

6. Quinn CC, Shardell MD, Terrin ML, Barr EA, Ballew SH, Gruber-Baldini AL. Cluster-randomized trial of a mobile phone personalized behavioral intervention for blood glucose control. Diabetes Care 2011 Sep;34(9):1934-1942 [FREE Full text] [doi: $10.2337 / \mathrm{dc11-0366}$ [Medline: 21788632]

7. Cui M, Wu X, Mao J, Wang X, Nie M. T2DM self-management via smartphone applications: A systematic review and meta-analysis. PLoS One 2016;11(11):e0166718 [FREE Full text] [doi: 10.1371/journal.pone.0166718] [Medline: 27861583]

8. Fu H, McMahon SK, Gross CR, Adam TJ, Wyman JF. Usability and clinical efficacy of diabetes mobile applications for adults with type 2 diabetes: A systematic review. Diabetes Res Clin Pract 2017 Sep;131:70-81. [doi: 10.1016/j.diabres.2017.06.016] [Medline: 28692830]

9. Jimenez G, Lum E, Car J. Examining diabetes management apps recommended from a Google search: Content analysis. JMIR Mhealth Uhealth 2019 Jan 16;7(1):e11848 [FREE Full text] [doi: 10.2196/11848] [Medline: $\underline{30303485}$ ]

10. Ristau RA, Yang J, White JR. Evaluation and evolution of diabetes mobile applications: Key factors for health care professionals seeking to guide patients. Diabetes Spectr 2013 Nov 15;26(4):211-215. [doi: 10.2337/diaspect.26.4.211]

11. Veazie S, Winchell K, Gilbert J, Paynter R, Ivlev I, Eden KB, et al. Rapid evidence review of mobile applications for self-management of diabetes. J Gen Intern Med 2018 Jul;33(7):1167-1176 [FREE Full text] [doi: 10.1007/s11606-018-4410-1] [Medline: 29740786]

12. Zachary W, Gupta H. Comparing type 2 diabetes self-management apps against the needs of low-income minority patients: Is there an implicit functionality bias? In: Proceedings of the 11th ACM Conference on Bioinformatics, Computational Biology, and Health Informatics. New York, NY: Association for Computing Machinery; 2020 Presented at: 11th ACM Conference on Bioinformatics, Computational Biology, and Health Informatics; August 30-September 2, 2020; Virtual event, USA. [doi: 10.1145/3388440.3414913]

13. Hou C, Xu Q, Diao S, Hewitt J, Li J, Carter B. Mobile phone applications and self-management of diabetes: A systematic review with meta-analysis, meta-regression of 21 randomized trials and GRADE. Diabetes Obes Metab 2018 Aug;20(8):2009-2013. [doi: 10.1111/dom.13307] [Medline: 29582538]

14. Carter BM, Barba B, Kautz DD. Culturally tailored education for African Americans with type 2 diabetes. Medsurg Nurs 2013;22(2):105-109, 123. [Medline: 23802497]

15. Ye Q, Khan U, Boren SA, Simoes EJ, Kim MS. An analysis of diabetes mobile applications features compared to AADE7TM: Addressing self-management behaviors in people with diabetes. J Diabetes Sci Technol 2018 Jul;12(4):808-816 [FREE Full text] [doi: 10.1177/1932296818754907] [Medline: 29390917]

16. Surkan PJ, Mezzanotte KS, Sena LM, Chang LW, Gittelsohn J, Trolle Lagerros Y, et al. Community-driven priorities in smartphone application development: Leveraging social networks to self-manage type 2 diabetes in a low-income African American neighborhood. Int J Environ Res Public Health 2019 Jul 30;16(15):2715 [FREE Full text] [doi: 10.3390/ijerph16152715] [Medline: 31366047] 
17. 2017 Neighborhood Health Profile for Southwest Baltimore. Baltimore, MD: Baltimore City Health Department; 2017 Jun. URL: https://health.baltimorecity.gov/sites/default/files/ NHP\%202017\%20-\%2051\%20Southwest\%20Baltimore\%20(rev\%206-9-17).pdf [accessed 2018-12-10]

18. Zachary WW, Michlig G, Kaplan A, Nguyen N, Quinn CC, Surkan PJ. Participatory design of a social networking app to support type II diabetes self-management in low-income minority communities. Proc Int Symp Hum Factors Ergon Healthc 2017 Jun;6(1):37-43 [FREE Full text] [doi: 10.1177/2327857917061010] [Medline: 31157286]

19. Brooke J. SUS: A 'quick and dirty' usability scale. In: Jordan PW, Thomas B, Weerdmeester B, McClelland IL, editors. Usability Evaluation in Industry. London, UK: Taylor \& Francis Ltd; 1996:189-194.

20. Sauro J. A Practical Guide to the System Usability Scale: Background, Benchmarks and Best Practices. Denver, CO: Measuring Usability LLC; 2011.

21. Braun V, Clarke V. Using thematic analysis in psychology. Qual Res Psychol 2006 Jan;3(2):77-101. [doi: 10.1191/1478088706qp063oa]

22. Saldaña J. The Coding Manual for Qualitative Researchers. 3rd edition. Thousand Oaks, CA: SAGE Publications; 2015.

23. Boeije H. A purposeful approach to the constant comparative method in the analysis of qualitative interviews. Qual Quant 2002 Nov 01;36(4):409. [doi: 10.4135/9781849209403.n920]

24. Hudson JL, Bundy C, Coventry PA, Dickens C. Exploring the relationship between cognitive illness representations and poor emotional health and their combined association with diabetes self-care. A systematic review with meta-analysis. $\mathrm{J}$ Psychosom Res 2014 Apr;76(4):265-274. [doi: 10.1016/j.jpsychores.2014.02.004] [Medline: 24630175]

25. Strandberg RB, Graue M, Wentzel-Larsen T, Peyrot M, Thordarson HB, Rokne B. Longitudinal relationship between diabetes-specific emotional distress and follow-up HbA1c in adults with type 1 diabetes mellitus. Diabet Med 2015 Oct;32(10):1304-1310 [FREE Full text] [doi: 10.1111/dme.12781] [Medline: 25865313]

26. Tullis TS, Stetson JN. A comparison of questionnaires for assessing website usability. In: Proceedings of the Usability Professional Association Conference. 2014 Jun Presented at: Usability Professional Association Conference; June 7-11, 2004; Minneapolis, MN p. 1-12 URL: http://uxmetricsgeek.com/wp-content/uploads/2017/06/UPA2004TullisStetson.pdf

27. Ayre J, Bonner C, Bramwell S, McClelland S, Jayaballa R, Maberly G, et al. Factors for supporting primary care physician engagement with patient apps for type 2 diabetes self-management that link to primary care: Interview study. JMIR Mhealth Uhealth 2019 Jan 16;7(1):e11885 [FREE Full text] [doi: 10.2196/11885] [Medline: $\underline{30664468}$ ]

28. Hood M, Wilson R, Corsica J, Bradley L, Chirinos D, Vivo A. What do we know about mobile applications for diabetes self-management? A review of reviews. J Behav Med 2016 Dec;39(6):981-994. [doi: 10.1007/s10865-016-9765-3] [Medline: 27412774]

29. Agarwal P, Mukerji G, Desveaux L, Ivers NM, Bhattacharyya O, Hensel JM, et al. Mobile app for improved self-management of type 2 diabetes: Multicenter pragmatic randomized controlled trial. JMIR Mhealth Uhealth 2019 Jan 10;7(1):e10321 [FREE Full text] [doi: 10.2196/10321] [Medline: $\underline{\text { 30632972] }}$

30. Fairbrother G, Kenney G, Hanson K, Dubay L. How do stressful family environments relate to reported access and use of health care by low-income children? Med Care Res Rev 2005 Apr;62(2):205-230. [doi: 10.1177/1077558704273805] [Medline: 15750177$]$

31. Guendelman S, Wier M, Angulo V, Oman D. The effects of child-only insurance coverage and family coverage on health care access and use: Recent findings among low-income children in California. Health Serv Res 2006 Feb;41(1):125-147 [FREE Full text] [doi: 10.1111/j.1475-6773.2005.00460.x] [Medline: 16430604]

32. Lazar M, Davenport L. Barriers to health care access for low income families: A review of literature. J Community Health Nurs 2018;35(1):28-37. [doi: 10.1080/07370016.2018.1404832] [Medline: 29323941]

33. Chapel JM, Ritchey MD, Zhang D, Wang G. Prevalence and medical costs of chronic diseases among adult Medicaid beneficiaries. Am J Prev Med 2017 Dec;53(6S2):S143-S154 [FREE Full text] [doi: 10.1016/j.amepre.2017.07.019] [Medline: 29153115]

34. Wu J, Ward E, Threatt T, Lu ZK. Progression to type 2 diabetes and its effect on health care costs in low-income and insured patients with prediabetes: A retrospective study using Medicaid claims data. J Manag Care Spec Pharm 2017 Mar;23(3):309-316. [doi: 10.18553/jmcp.2017.23.3.309] [Medline: 28230458]

35. Tadic V, Ashcroft R, Brown JB, Dahrouge S. The role of social workers in interprofessional primary healthcare teams. Healthc Policy 2020 Aug;16(1):27-42 [FREE Full text] [doi: 10.12927/hcpol.2020.26292] [Medline: 32813638]

36. Cassarino M, Robinson K, Quinn R, Naddy B, O'Regan A, Ryan D, et al. Impact of early assessment and intervention by teams involving health and social care professionals in the emergency department: A systematic review. PLoS One 2019;14(7):e0220709 [FREE Full text] [doi: 10.1371/journal.pone.0220709] [Medline: 31365575]

37. Haomiao J, Santana A, Lubetkin EI. Measuring risk perception among low-income minority primary care patients. J Ambul Care Manage 2004;27(4):314-327. [doi: 10.1097/00004479-200410000-00004] [Medline: 15495744]

38. O'Brien MJ, Moran MR, Tang JW, Vargas MC, Talen M, Zimmermann LJ, et al. Patient perceptions about prediabetes and preferences for diabetes prevention. Diabetes Educ 2016 Dec;42(6):667-677 [FREE Full text] [doi: 10.1177/0145721716666678] [Medline: 27621093] 
39. Tahamtan I, Pajouhanfar S, Sedghi S, Azad M, Roudbari M. Factors affecting smartphone adoption for accessing information in medical settings. Health Info Libr J 2017 Jun;34(2):134-145 [FREE Full text] [doi: 10.1111/hir.12174] [Medline: 28406547]

40. Mobile fact sheet. Pew Reseach Center. Washington, DC: Pew Research Center; 2019 Jun 12. URL: https://www. pewresearch.org/internet/fact-sheet/mobile/ [accessed 2021-01-28]

41. Kitsiou S, Paré G, Jaana M, Gerber B. Effectiveness of mHealth interventions for patients with diabetes: An overview of systematic reviews. PLoS One 2017;12(3):e0173160 [FREE Full text] [doi: 10.1371/journal.pone.0173160] [Medline: 28249025]

42. Jimenez G, Lum E, Huang Z, Theng YL, Boehm BO, Car J. Reminders for medication adherence in type 2 diabetes management apps. J Pharm Pract Res 2020 Jan 29;50(1):78-81 [FREE Full text] [doi: 10.1002/jppr.1595]

43. Huang Z, Lum E, Jimenez G, Semwal M, Sloot P, Car J. Medication management support in diabetes: A systematic assessment of diabetes self-management apps. BMC Med 2019 Jul 17;17(1):127 [FREE Full text] [doi: 10.1186/s12916-019-1362-1] [Medline: 31311573]

44. Johnson D, Jones C, Scholes L, Colder Carras M. Videogames and Wellbeing: A Comprehensive Review. Melbourne, Australia: Young and Well Cooperative Research Centre; 2013. URL: https://eprints.qut.edu.au/105915/1/ 2013\%2BCRC\%2BReport\%2BVideogames_and_Wellbeing.pdf [accessed 2021-01-28]

45. McGonigal J. Reality Is Broken: Why Games Make Us Better and How They Can Change the World. New York, NY: Penguin Books; 2011.

46. Pereira P, Duarte E, Rebelo F, Noriega P. A review of gamification for health-related contexts. In: Proceedings of the International Conference of Design, User Experience, and Usability. Cham, Switzerland: Springer International Publishing; 2014 Presented at: International Conference of Design, User Experience, and Usability; June 22-27, 2014; Heraklion, Greece p. 742-753 URL: https://link.springer.com/content/pdf/10.1007\%2F978-3-319-07626-3_70.pdf [doi: 10.1007/978-3-319-07626-3 70]

47. King D, Greaves F, Exeter C, Darzi A. 'Gamification': Influencing health behaviours with games. J R Soc Med 2013 Mar;106(3):76-78 [FREE Full text] [doi: 10.1177/0141076813480996] [Medline: 23481424]

48. Munson S, Poole E, Perry D, Peyton T. Gamification and health. In: Walz SP, Deterding S, editors. The Gameful World: Approaches, Issues, Applications. Cambridge, MA: The MIT Press; 2015:597-623.

49. Martínez-Pérez B, de la Torre-Díez I, López-Coronado M. Mobile health applications for the most prevalent conditions by the World Health Organization: Review and analysis. J Med Internet Res 2013 Jun 14;15(6):e120 [FREE Full text] [doi: 10.2196/jmir.2600] [Medline: 23770578]

\section{Abbreviations \\ DNT: Diabetes Networking Tool \\ ER: emergency department \\ $\mathbf{H b A}_{1 \mathbf{c}}$ : glycated hemoglobin \\ mHealth: mobile health \\ SUS: System Usability Scale \\ T2DM: type 2 diabetes mellitus}

Edited by G Eysenbach; submitted 12.02.20; peer-reviewed by S Veazie, E Bellfield, G Jimenez, H Fu; comments to author $31.08 .20 ;$
revised version received 18.10.20; accepted 17.12.20; published 26.02.21
Please cite as:
Barber-Gumbs T, Trolle Lagerros Y, Sena LM, Gittelsohn J, Chang LW, Zachary WW, Surkan PJ
Perspectives From Underserved African Americans and Their Health Care Providers on the Development of a Diabetes Self-Management
Smartphone App: Qualitative Exploratory Study
JMIR Form Res $2021 ; 5(2):$ : 18224
URL: $\underline{\text { https://formative.jmir.org/2021/2/e18224 }}$
doi: $\underline{10.2196 / 18224}$
PMID: $\underline{33635279}$

(C)Tai Barber-Gumbs, Ylva Trolle Lagerros, Laura M Sena, Joel Gittelsohn, Larry W Chang, Wayne W Zachary, Pamela J Surkan. Originally published in JMIR Formative Research (http://formative.jmir.org), 26.02.2021. This is an open-access article distributed under the terms of the Creative Commons Attribution License (https://creativecommons.org/licenses/by/4.0/), which permits unrestricted use, distribution, and reproduction in any medium, provided the original work, first published in JMIR Formative 
Research, is properly cited. The complete bibliographic information, a link to the original publication on http://formative.jmir.org, as well as this copyright and license information must be included. 